Sustainable Structures

ISSN: 2789-3111 (Print); ISSN: 2789-312X (Online)

http://www.sustain-dpl.com/picnews.asp?id=155

DOI: $10.54113 /$ j.sust.2021.000005

ORIGINAL ARTICLE

\title{
Research on dynamic characteristics test of wooden floor structure for gymnasium
}

\author{
Yuhao Zhou $^{\mathrm{a}}$, Yujie Huang ${ }^{\mathrm{a}}$, Usama Sayed ${ }^{\mathrm{b}}$, Zheng Wang, \\ ${ }^{a}$ College of Materials Science and Technology, Nanjing Forestry University, Nanjing 210037, China. \\ bJoint International Research Laboratory for Bio-composite Building Materials and Structures, Nanjing Forestry University, \\ Nanjing 210037, China. \\ *Corresponding Author: Zheng Wang. Email: wangzheng63258@163.com.
}

\begin{abstract}
In order to better evaluate the structural performance of the wooden floor used in the gymnasium and realize the structural optimization design, this research considered two gymnasium's floors in Nanjing as the research object and used the transient excitation method to test the natural frequency and damping ratio parameters of the three types of floor structures. The results showed that three kinds of floor structures all meet the requirements of building comfort; under the premise that the types and specifications of the constituent materials were the same, the order of the damping ratios of the three kinds of floor structures from large to small was: the fixed floor structure with double-layer load distribution strip, the suspended floor structure with single-layer load distribution strip, and the suspended floor structure with double-layer load distribution strip; compared with the fixed floor structure, the suspended floor structure had low damping ratio characteristics, the energy dissipation was slow during structural vibration, which means its impact absorption rate was small, and its impact buffering ability was good. The integral structure had good resilience performance; compared with the floor structure using single-layer load distribution strip. The floor structure using a double-layer load distribution strip had a low damping ratio characteristic. The absorption rate of the structure was small and the resilience performance was good. The research conclusion had certain engineering application value.
\end{abstract}

Keywords: Gymnasium; Floor structure; Transient excitation method; Natural frequency; Damping ratio

\section{Introduction}

In recent years, various countries have attached great importance to the development of cultural and sports undertakings. As the main place for fitness exercises, gymnasiums have attracted more and more attention. The wooden floor is the most basic unit in the gymnasium, which plays a vital role in the performance of the gymnasium. Researchers have conducted relevant studies on the dynamic characteristics of the floor structure and have gained many achievements [1-2]. Cai et al. [3-4] used the lateral vibration method to evaluate the performance of solid wood flooring by detecting the frequency and damping ratio of the floor. Chui et al. [5] explored the influence of different support conditions on the static deflection and natural frequency of wooden floors through a finite element model. According to the theory of structural flexibility matrix difference, Chen [6] used the impulse hammering experiment method and finite element simulation technology to study the non-destructive testing of the wooden floor structure and proposed a solution to detect the damage of the wooden floor 
structure. Zhao et al. [7] obtained the forced vibration response data through the forced vibration test and finite element numerical simulation of the wooden floor. The application results showed that: with the help of the forced vibration response data, the calculation of its curvature could better identify the damage of the wooden floor structure, Damage location and degree of damage. Rijal et al. [8] used force hammer excitation and evaluated the vibration performance of wooden floor modules with spans of $6 \mathrm{~m}$ and $8 \mathrm{~m}$ based on dynamic characteristic parameters such as natural frequency, damping ratio, and mode shape. Matsushitas et al. [9] established a finite element model of the piezoelectric device and the floor structure and proposed a prediction method to reduce the floor vibration using the control system of the thin-film piezoelectric device. Casagrande et al. [10] studied three methods of evaluating the vibration performance of wooden floors: numerical methods, analytical methods, and test methods. He found that internal partitions and non-structural elements have a great impact on the dynamic characteristics of the floor, especially the mode shape, frequency and damping. Hua et al. [11] conducted impact tests on shock-absorbing cushions with different structural parameters and explored the relationship between the structural parameters of sports floor shock-absorbing cushions and the impact force through two numerical simulation algorithms based on BP neural network and SPSS multiple linear regression equation.

Researchers have used a variety of different methods to study the dynamic characteristics of the floor, but most of them are computational modal and laboratory experimental studies. This research intends to carry out on-site dynamic characteristics test research on the wooden floor systems in two gymnasiums in Nanjing, focusing on the analysis and comparison of the natural frequency and damping ratio parameters of the wooden floor system to provide technical support for the performance evaluation and optimization design of the wooden floor structure for the gymnasium.

\section{Materials and Method}

\subsection{Floor Structure Design}

The structure of the wooden floor for the gymnasium is mainly composed of the wooden flooring face layer, the load distribution panel, the isolation layer, the load distribution strip, and the cushion block. According to the different uses, performance index requirements, and cost of sports wood flooring, the materials used in each structural layer will be different. The wooden flooring face layer refers to the floor placed on the surface in the floor structure. The load distribution panel is placed between the wooden flooring face layer and the load distribution strip in the floor structure to play a bearing role. The isolation layer is located between the wooden flooring face layer and the load distribution panel to isolate or prevent moisture. It also can be placed between the load distribution strip and the foundation of the building structure. The load distribution strip is a strip material placed on the lower layer of the floor structure to play a supporting role. The cushion block materials are placed between each layer of the floor structure or between the foundations of the building structure to play a damping role [12].

This research involves three wooden floor structures used in Gymnasium $\mathbf{J}$ and Gymnasium $\mathrm{Y}$, which are located in Nanjing, China. Gymnasium $\mathrm{J}$ is divided into area A and B. The floor structure of area $\mathrm{A}$ is a suspended structure with double-layer load distribution strip, and the floor structure of area $\mathrm{B}$ is a fixed structure with double-layer load distribution strip. The floor structure of Gymnasium $\mathrm{Y}$ is a suspended structure with single-layer load distribution strip.

\subsubsection{Floor Structure of Area A in Gymnasium J}

Fig.1 shows a suspended structure with double-layer load distribution strip, including the wooden flooring face layer, the load distribution panel, the second-layer load distribution strip, the cushion block, the first-layer load distribution strip, the leveling block, the cushion gasbag, and the isolation layer. The wooden flooring face layer is a $22 \mathrm{~mm}$ thick solid maple wood panel. The load distribution panel is located under the wooden flooring face layer, which plays a bearing role, and plywood of $12 \mathrm{~mm}$ thick is applied. The second-layer load distribution strips and the first-layer load distribution strips underneath are cross-laid at a certain interval to make the overall structure more stable. The load distribution strips are made of laminated veneer lumber (LVL), with $78 \mathrm{~mm}$ wide and $30 \mathrm{~mm}$ thick. The load distribution strips are connected by the cushion blocks, which are made of 
natural rubber. The leveling blocks are laid under the first-layer load distribution strip, which is made of plywood. The thickness of leveling block can be adjusted (the $12 \mathrm{~mm}$ shown in Fig.1 is just for reference), and it plays a role in leveling the foundation. The cushion gasbags are made of plastisol with Shore hardness of 65 are set under the leveling blocks. With a special structure, the cushion gasbag has good shock-absorbing performance. The isolation layer is set above the foundation, also known as the damp-proof course, which is used for the waterproof coating to isolate and prevent moisture. Each structural layer in Fig. 1 is connected by bolts or phenolic glue.

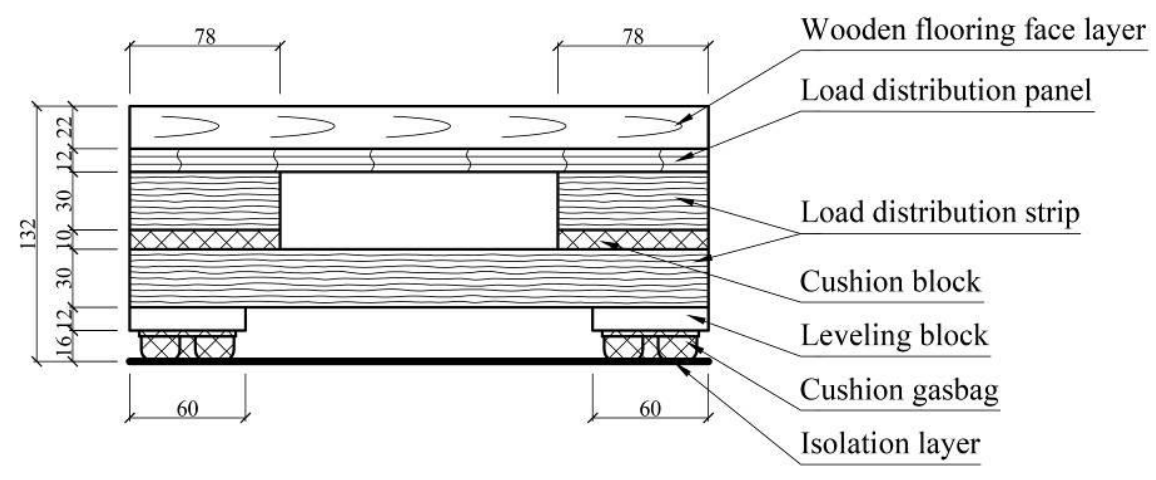

Fig. 1. Floor structure of area A in Gymnasium J

\subsubsection{Floor Structure of Area B in Gymnasium J}

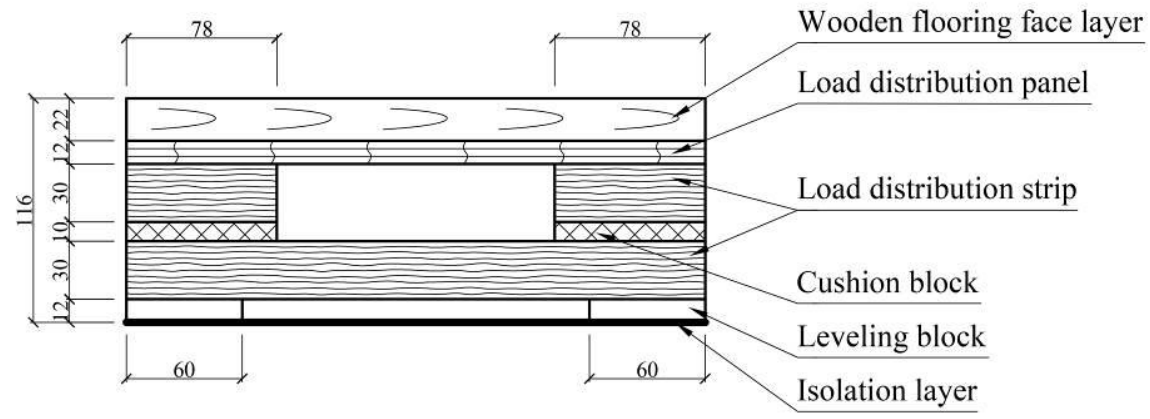

Fig. 2. Floor structure of area B in Gymnasium $J$

Fig.2 shows a fixed structure with double-layer load distribution strip, including the wooden flooring face layer, the load distribution panel, the second-layer load distribution strip, the cushion block, the first-layer load distribution strip, the leveling block, and the isolation layer (not shown in Fig.2). The dimensions, materials, and the connection between the layers of the floor structure in area $\mathrm{B}$ are the same as those in area A, but the leveling blocks at the bottom of the structure are placed directly above the isolation layer without the cushion gasbags in the middle.

\subsubsection{Floor Structure in Gymnasium Y}

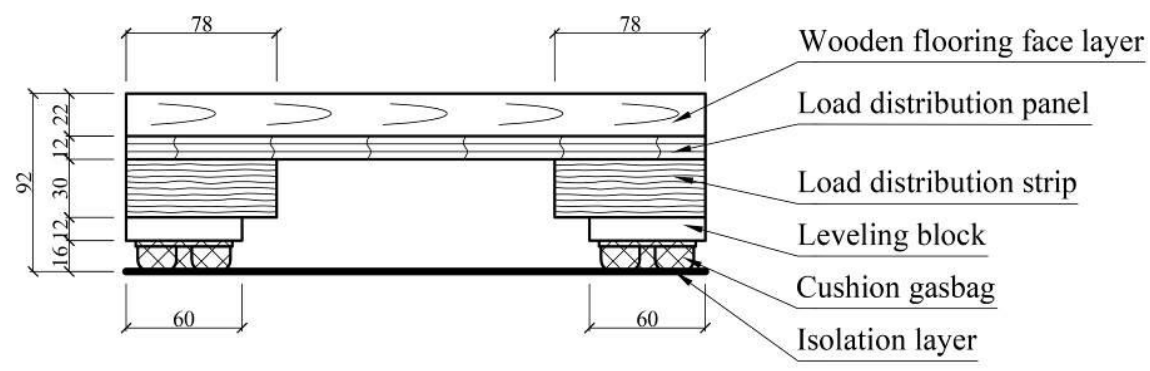

Fig. 3. Floor structure in Gymnasium Y

Fig.3 shows a suspended structure with single-layer load distribution strip, including the wooden flooring face layer, the load distribution panel, the load distribution strip, the leveling block, the cushion gasbag, and the isolation layer (not shown in Fig.3). The dimensions, materials, and the 
connection between the layers of the floor structure in Gymnasium Y are the same as those in area A of Gymnasium J. The difference is that there is only one layer of load distribution strips in the floor structure in Gymnasium Y, which are laid at a certain interval.

\subsection{Test Object and Instrument}

The objects of this research are the floor structures of area A and B in Gymnasium $\mathbf{J}$, and the floor structure of Gymnasium Y. The test instruments: CRAS vibration and dynamic signal acquisition and analysis system, AZ804-B signal conditioner, AZ308 signal acquisition box, CRAS software and computer (produced by Nanjing Anzheng Software Engineering Co., Ltd.); CA-YD-125 accelerometer, its sensitivity factor is $14.9 \mathrm{~V} \cdot \mathrm{s} 2 / \mathrm{m}$; rubber hammer; tape measure.

\subsection{Test Method and Principle}

The test adopts the transient excitation method, using a rubber hammer as the excitation source to knock the measuring point on the wooden floor of the gymnasium, the acceleration sensor converts the picked-up vibration signal into an electrical signal. The signal is amplified and filtered, and converted into a digital signal by CARS. The first-order frequency is obtained in the spectrogram, and the attenuation vibration curve is obtained in the waveform diagram.

The receiving device for vibration measurement is a vibration pickup, also called a sensor or transducer. Vibration pickup is a transducer device that converts vibration displacement, velocity, acceleration, and other non-electricity signals into electric energy output. This test uses the CA-YD125 accelerometer, piezoelectric crystal elements, and the principle of "piezoelectric effect" in which the crystal is deformed by vibration or impact, and can work in a wide frequency range [13]. The block diagram of the test principle is shown in Fig. 4.

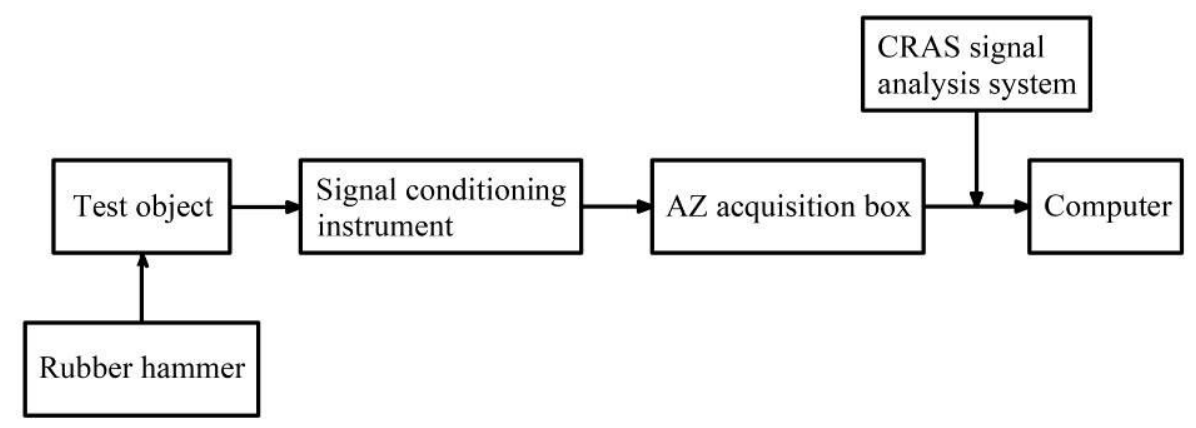

Fig. 4. Principle block diagram of dynamic characteristic test

\subsection{Test Step}

(1)Select an area in the tested gymnasium to divide the grid, and arrange the location of the measurement points according to Fig.5. Connect and debug the test system.

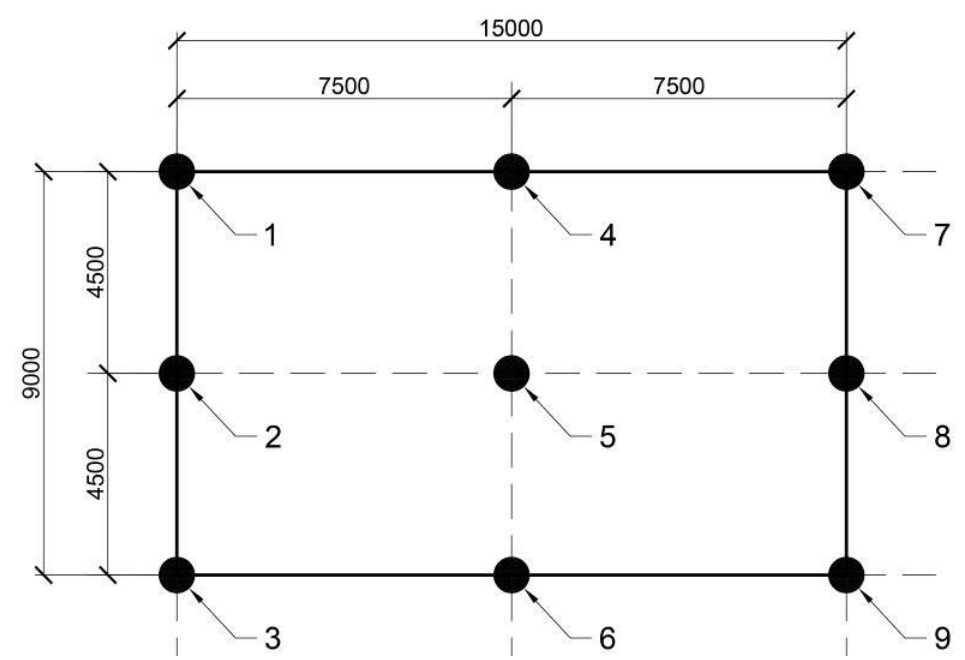

Fig. 5. Layout of plane measuring points for dynamic characteristic test 
(2)After the test system is debugged, used double-sided tape to paste the acceleration sensor on the measuring point, and hit the floor around the sensor with a rubber hammer to make it vibrate freely. The CARS signal test acquisition and analysis system collect and analyzes the vibration signal, then the first-order natural frequency and attenuated vibration waveform diagram of the corresponding gymnasium floor structure can be obtained in the computer.

(3)Process the obtained first-order frequency spectrum and amplitude attenuation waveform. According to the acceleration amplitude in the attenuated vibration waveform diagram shown in Fig.6, the vibration damping ratio $\zeta$ of floor structure is calculated according to formula (1):

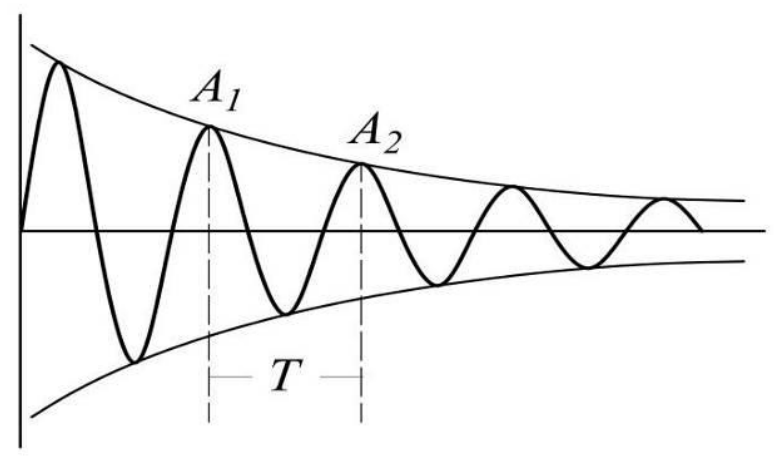

Fig. 6. Diagram of attenuated vibration waveform

$$
\delta=\frac{\ln \left(A_{1} / A_{3}\right)}{2}, \quad \zeta=\frac{\delta}{2 \pi}
$$

In this formula: $\delta$ is the logarithmic amplitude reduction coefficient, dimensionless; $A_{1} 、 A_{3}$ are the amplitudes of the corresponding wave crest, $\mathrm{mm} / \mathrm{s} 2 ; \zeta$ is the damping ratio, dimensionless.

\section{Results and Analysis}

\subsection{Natural Frequency}

\subsubsection{Test Results of Natural Frequency}

The measurement points 1-9 of different floor structure were tested by the transient excitation method. The first-order frequency spectrum was obtained as shown in Fig.7. In order to ensure the accuracy and rationality of the test results, each measurement point had been tested plenty of times. The natural frequency of each measuring point of different floor structures is shown in Table 1.

Table 1. Natural frequency of different floor structures

\begin{tabular}{cccc}
\hline \multirow{2}{*}{ Measuring point } & \multicolumn{3}{c}{ Natural frequency $(\mathrm{Hz})$} \\
\cline { 2 - 4 } & Area A in Gymnasium J & Area B in Gymnasium J & Gymnasium Y \\
\hline 1 & 66.56 & 84.38 & 68.13 \\
2 & 65.94 & 92.50 & 68.75 \\
3 & 63.23 & 88.70 & 69.01 \\
4 & 64.14 & 90.52 & 70.85 \\
5 & 67.74 & 85.88 & 67.52 \\
6 & 68.01 & 91.43 & 72.95 \\
7 & 66.32 & 92.00 & 66.34 \\
8 & 62.57 & 86.77 & 72.51 \\
9 & 65.08 & 88.19 & 70.66 \\
Average value & 65.51 & 88.93 & 69.86 \\
CV (\%) & 2.8 & 3.2 & 2.9 \\
\hline
\end{tabular}




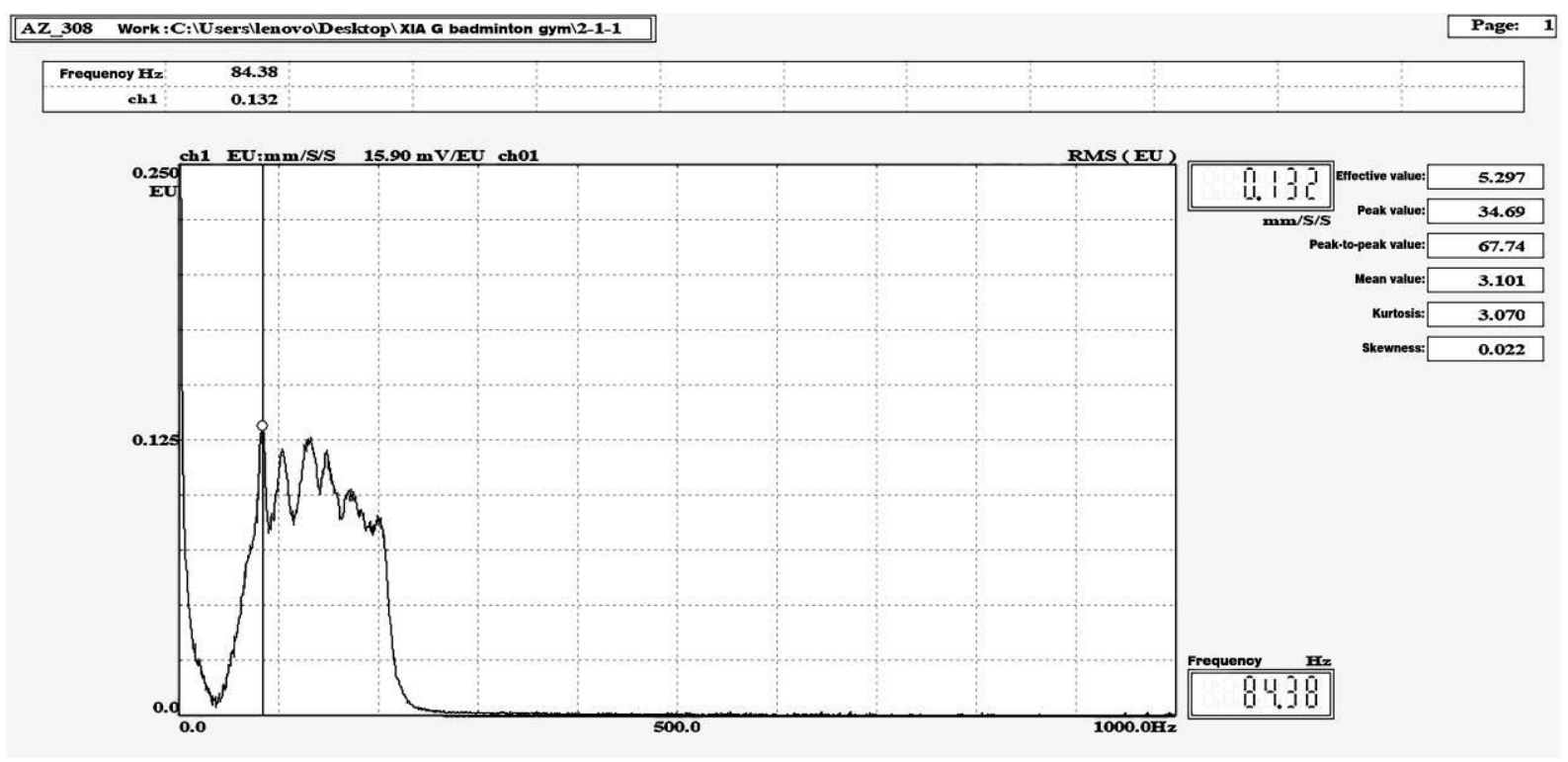

Fig. 7. First-order spectrogram of measuring point 1 of area B in Gymnasium $\mathbf{J}$

\subsubsection{Analysis of Natural Frequency}

The natural frequency refers to the vibration frequency of the elastic body or the elastic system itself. For multi-particle systems, ignoring the influence of damping, the natural frequency is related to its own mass, distribution, boundary support conditions, and the form of vibration [14]. The lower vertical natural frequency of the structure will induce vibration comfort problems caused by humans [15-17]. At present, there is no relevant limit on the natural vibration frequency of wooden floor used in gymnasiums by domestic standards. In this paper, the relevant research and norms of the natural frequency of building floor structure were used as references to analyze and evaluate the natural frequencies of these three floor structures. Engineering research showed that the frequency of various human activities was generally concentrated in $1 \sim 3 \mathrm{~Hz}[18]$. In the floor vibration caused by human activities, when the natural frequency of the floor was in the range of $3-8 \mathrm{~Hz}$, the resonance reaction was generally the main reason for the vibration, and people would feel uncomfortable when moving on the floor [19]; when the natural frequency of the floor was greater than 8-9 Hz, human activities would not cause resonance response, such floor could be considered as comfortable [20]. In the relevant codes for the control of natural frequency of building floor structures, such as JGJ 99-2015 "Technical Regulations for Steel Structures of High-Rise Civil Buildings" [21], the vertical natural frequency of steel structure floors shall not be less than $3 \mathrm{~Hz}$; GB 50010-2010 "Code for Design of Concrete Structures" [22] stipulates the following requirements for the vertical natural vibration frequency of concrete floor structures: residences and apartments should not be lower than $5 \mathrm{~Hz}$, offices and hotels should not be lower than $4 \mathrm{~Hz}$, and large-span public buildings should not be lower than $3 \mathrm{~Hz}$.

It can be seen from Table 1 that the natural frequency of the floor structure of area $\mathrm{A}$ in Gymnasium J was about $65.51 \mathrm{~Hz}$, the natural frequency of floor structure of area B in Gymnasium J was about $88.93 \mathrm{~Hz}$, and the natural frequency of the floor structure of Gymnasium Y was about $69.86 \mathrm{~Hz}$. These natural frequency values were much higher than the above-mentioned relevant limits, which met the comfort requirements of the building structure. In addition, the coefficients of variation $(\mathrm{CV})$ of the natural frequencies of the three groups of tests were: $2.8 \%, 3.2 \%$, and $2.9 \%$, all of which were less than $15 \%$, indicating that the data obtained in the test was reliable.

\subsection{Damping Ratio}

\subsubsection{Test Results of Damping Ratio}

The measurement points 1-9 of different floor structure were tested by the transient excitation method, and the amplitude attenuation waveform diagram was obtained as shown in Fig.8. In order to 
ensure the accuracy and rationality of the test results, each measurement point had been tested plenty of times. The damping ratio of each measuring point of different floor structures is shown in Table 2 .

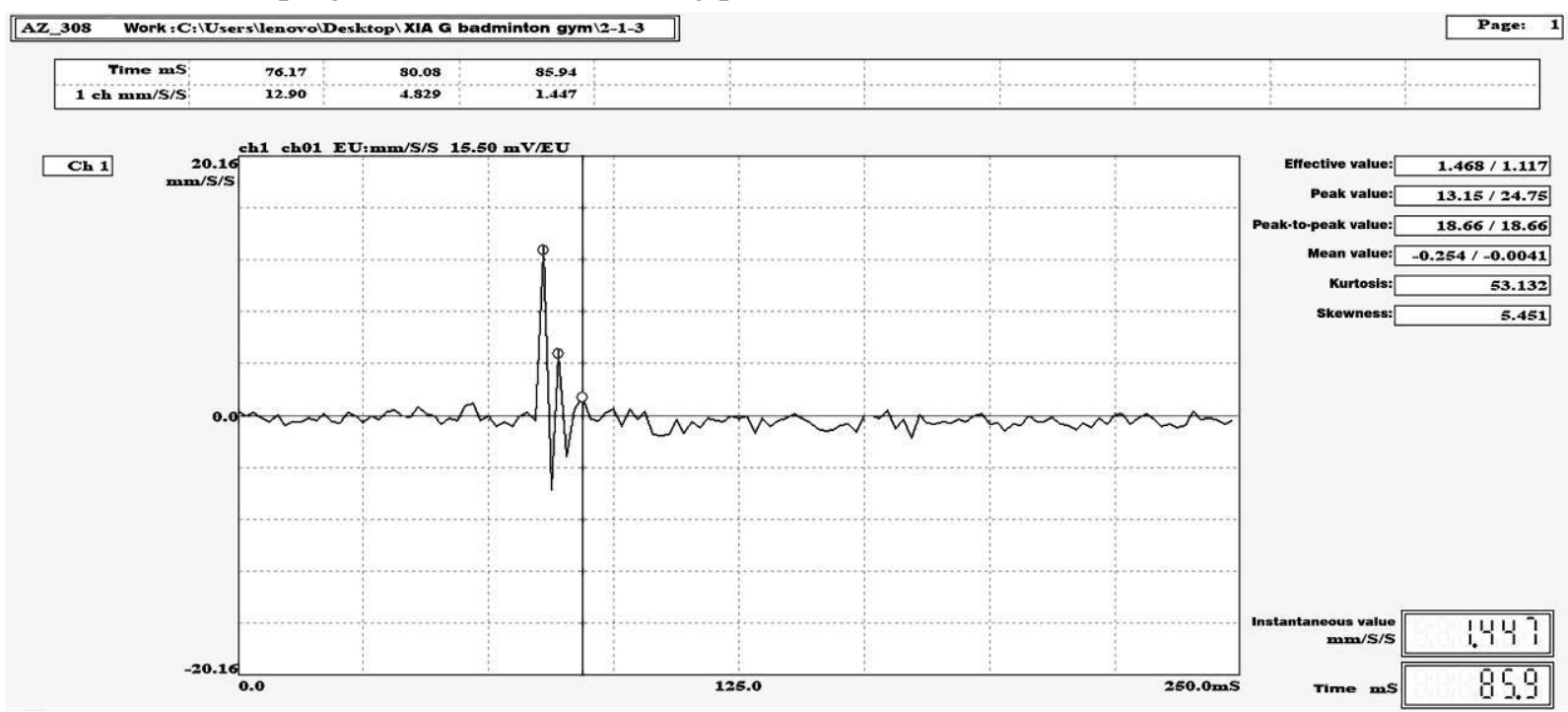

Fig. 8. Amplitude attenuation waveform of measuring point 1 in area B of Gymnasium $J$

Table 2. Calculation results of damping ratio of floor structure

\begin{tabular}{cccc}
\hline \multirow{2}{*}{ Measuring point } & \multicolumn{3}{c}{ Damping ratio } \\
\cline { 2 - 4 } & Area A in Gymnasium J & Area B in Gymnasium J & Gymnasium Y \\
\hline 1 & 0.088 & 0.174 & 0.095 \\
2 & 0.097 & 0.188 & 0.109 \\
3 & 0.090 & 0.161 & 0.098 \\
4 & 0.094 & 0.157 & 0.100 \\
5 & 0.092 & 0.190 & 0.115 \\
6 & 0.081 & 0.189 & 0.106 \\
7 & 0.080 & 0.190 & 0.107 \\
8 & 0.102 & 0.163 & 0.110 \\
9 & 0.085 & 0.171 & 0.106 \\
Average value & 0.090 & 0.176 & 0.105 \\
CV (\%) & 7.6 & 7.3 & 5.7 \\
\hline
\end{tabular}

\subsubsection{Analysis of Damping Ratio}

Damping is a parameter that reflects the characteristics of energy dissipation in the vibration process of a structural system [23]. In the design of the vibration isolation structure of the mechanical system, the reasonable use of damping technology can significantly improve the effect of vibration isolation and damping [24]. The structural damping ratio is used to express the magnitude of structural damping, which is usually obtained by actual measurement or experiment [25]. The larger damping ratio of the structure, the faster the structure will dissipate energy during the vibration process, which means that the structure has a poorer ability to transmit vibration and has better vibration damping performance. However, correspondingly, the poorer the structure's ability to transmit vibrations, the poorer the structure's ability to cushion shocks, and it will not have a better cushioning effect when impacted by external forces.

The comparison of the damping ratio of the three gymnasium floor structures is shown in Fig.9. According to Tab.2 and Fig.9, the average damping ratio of the floor structure of area $\mathrm{B}$ in Gymnasium J was the largest, which was 0.176; Gymnasium Y took second place, with 0.105; area A 
in Gymnasium $\mathbf{J}$ had the smallest damping ratio, which was 0.090 . The average damping ratio of the floor structure of area B in Gymnasium $\mathbf{J}$ was about twice that of the other two structures. Combined with Fig.1, Fig.2, and Fig.3, it could be seen that the suspended floor structure was far better than the fixed floor structure in terms of impact buffering capacity. The average damping of the floor structure of Gymnasium Y was 16.7\% larger than that of area A in Gymnasium J. In combination with Fig.1 and Fig.3, it could be seen that the floor structure with double-layer load distribution strip was better than the floor structure with single-layer load distribution strip in terms of impact buffering capacity. In addition, the coefficients of variation of the natural frequencies of the three groups of tests were: $7.6 \%, 7.3 \%$, and $5.7 \%$, all of which were less than $15 \%$, indicating that the data obtained in the test was reliable.

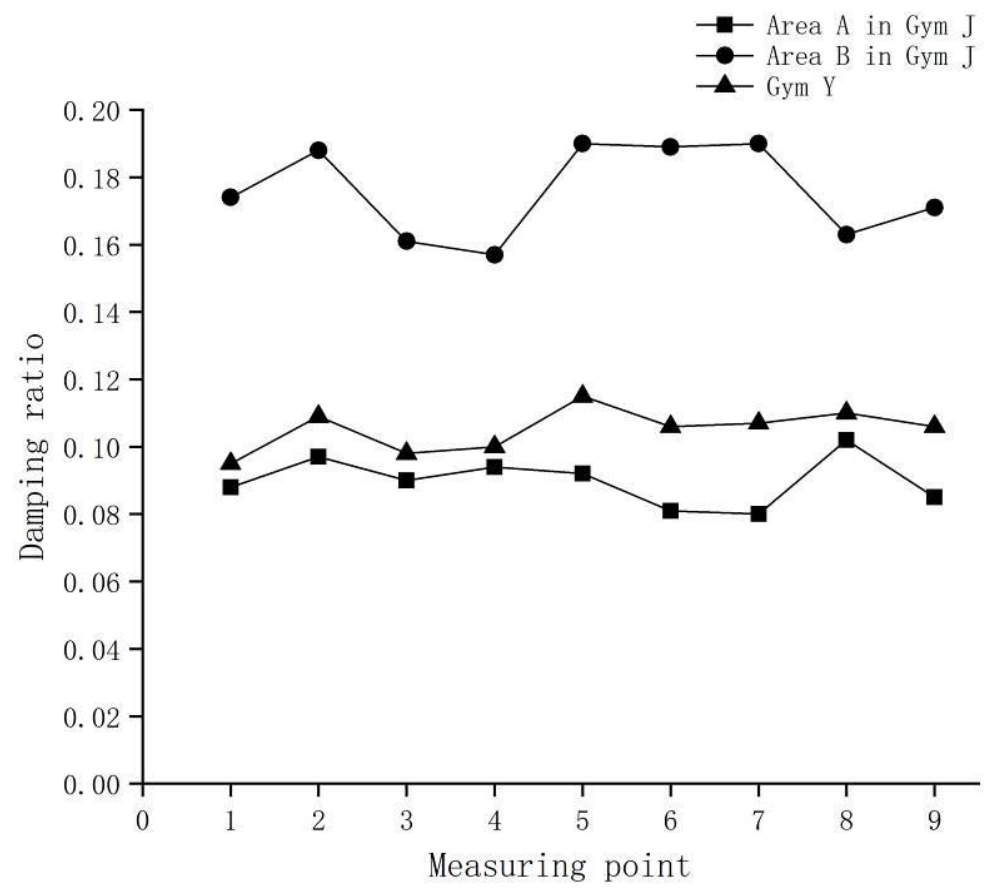

Fig. 9. Comparison of damping ratio of three gymnasium floor structures

\section{Conclusions}

Wooden floors for gymnasiums were divided into suspended and fixed according to the installation method, and they were also divided into single-layer structure and multi-layer structure according to the structure type. In this study, the dynamic characteristics of different types of floor structures were tested on the premise that the types and specifications of the constituent materials and the connection between the layers are the same. Through testing and analysis, this research mainly draws the following conclusions:

1) The natural frequencies of the three floors structures in this test all met the requirements of building comfort.

2) Among the three types of floor structures, the suspended structure with double-layer load distribution strip had the smallest damping ratio, which means the structure had better impact buffering capacity and resilience performance and was more suitable for large-scale stadiums that require high levels of competition.

3) The floor structure with suspended and multi-layer structure had a lower damping ratio and slow energy dissipation during structural vibration. The impact absorption rate of the structure was small and the structure had good impact buffering capacity, which could provide better protection for athletes.

4) The CRAS vibration and dynamic signal acquisition and analysis system and related test methods used in this study had the characteristics of simple operation, strong engineering application, and high data reliability. 


\section{Acknowledgement}

This study was funded by the Science and Technology Project for Policy Guidance of Jiangsu Province (SZ-LYG 2020016).

\section{Conflicts of Interest}

We have no conflict of interest for this paper.

\section{References}

[1] Wang HL, Zhou ZF, He JC, Li L. The relativity between sports physiology and biochemistry indexes of athletes and functional property of wooden sports flooring. Scientia Silvae Sinicae 2020; 56(1): 172-179. https://doi.org/10.11707/j.1001-7488.20200117.

[2] Yu HL. Wooden floor paving method for gymnasiums. Forestry Machinery \& Woodworking Equipment 2019; 47(4): 47-50. https://doi.org/10.13279/j.cnki.fmwe.2019.0046.

[3] Cai ZY, Hunt MO, Ross RJ, Wang XP, Soltis LA. Pilot study to examine use of transverse vibration nondestructive evaluation for assessing floor systems. Forest Products Journal 2002; 52(1): 89-93. https://doi.org/10.1023/A:1021182504650.

[4] Soltis LA, Wang XP, Ross RJ, Hunt MO. Vibration testing of timber floor systems. Forest Products Journal 2002; 52(10): 75-82. https://doi.org/10.1007/S00226-002-0152-6.

[5] Chui YH, Pirzada G, Jiang L, Hu LJ. Influence of end support conditions on static and dynamic response of wood floor. Forest Products Journal 2004; 54(12): 256-261. https://doi.org/10.1111/j.1439-0329.2004.00 380.x.

[6] Cheng X. Non-destructive testing of wood floor flaws and its finite-element dynamic analysis. Beijing Forest University, Beijing, China. 2007.

[7] Zhao D, Chen S, Zhao J. Study on damage identification of wood-floor structure based on response of forced vibration. Journal of West China Forestry Science 2013; 42(4): 14-19. https://doi.org/10.16473/j.cnk i.xblykx1972.2013.04.004.

[8] Rijal R, Samali B, Shrestha R, Crews K. Experimental and analytical study on dynamic performance of timber floor modules (timber beams). Construction and Building Materials 2016; 122: 391-399. https://doi. org/10.1016/j.conbuildmat.2016.06.027.

[9] Matsushita H, Yoshioka H. Prediction method of floor vibration reduction by control system using film type piezo-electric device. AIJ Journal of Technology and Design 2017; 23(53): 181-184. https://doi.org/10 .3130/aijt.23.181.

[10] Casagrande D, Giongo I, Pederzolli F, Franciosi A, Piazza M. Analytical, numerical and experimental assessment of vibration performance in timber floors. Engineering Structures 2018; 168: 748-758. https://d oi.org/10.1016/j.engstruct.2018.05.020.

[11] Hua J, Zhang H, Wang HL, Liu YN, Liu YC. Impact experiment and algorithm comparison of sports floor cushion. Journal of Northeast Forestry University 2020; 48(6): 69-74. https://doi.org/10.13759/j.cnki.dlxb. 2020.06.015.

[12] GB/T 20239-2015. Wooden flooring for gymnasium. Standards Press of China, Beijing, 2015.

[13] Lu TH, Wang TF. Noise and vibration control equipment and material selection manua. China Machine Press, Beijing, 1999; ISBN: 9787111070344.

[14] Cui KQ. Safety engineering dictionary. Chemical Industry Press, Beijing, 1995; ISBN: 9787502513719.

[15] Lou Y, Huang J, Lu ZC. Vibration comfort design of floor system. Science Press, Beijing, 2012; ISBN: 9787030334657.

[16] Xie WB, Ding YW, Wang Z, Wang YL, Yang J, Zhao TC. Modal test and finite element model of floor of wooden building. China Forest Products Industry 2019; 46(4): 17-22. https://doi.org/10.19531/j.issn10015299.201906004.

[17] Zhang ZY, Zhou HB. A Tentative analysis on human-induced vibration performances of timber floors. China Forest Products Industry 2020; 57(7): 19-23. https://doi.org/10.19531/j.issn1001-5299.202007006.

[18] Lu CH, Jing WL, Song ZG. Study on natural frequency of concrete floor based on vibration serviceability. Building Science 2010; 26(7): 43-46. https://doi.org/10.13614/j.cnki.11-1962/tu.2010.07.011.

[19] Du RJ, Shi WX, Wang PF. Analysis on the vertical vibration of floor slab based on comfort index. Low Temperature Architecture Technology 2009; 31(11): 45-47. https://doi.org/10.3969/j.issn.1001-6864.2009.1 1.018 .

[20] Lu WD, Liu XC, Wen JG, Wang T. Floor slab design method based on the vibration comfort degree. Journal of Nanjing Tech University (Natural Science Edition) 2008; 30(01): 16-18. https://doi.org/10.3969 /j.issn.1671-7627.2008.01.004.

[21] JGJ 99-2015. Technical regulations for steel structures of high-rise civil buildings. China Architecture \& Building Press, Beijing, 2015. 
[22] GB50010-2010. Code for Design of Concrete Structures. China Architecture \& Building Press, Beijing, 2010.

[23] Wang GY. Vibration of building structures. Science Press, Beijing, 1978; ISBN: 15031·176.

[24] Dai DP. Engineering application of damping technology. Qinghua University Press, Beijing, 1991; ISBN: 7-302-00877-9.

[25] Xue SZ, Wang SX, Liu YC. Selection of earthquake waves and values of damping ratio for space structures in aseismic analysis. Spatial Structures 2008; 14(03): 3-8. https://doi.org/10.13849 /j.issn.1006-6578.2008. 03.002 . 